\title{
An updated review on the neuropsychological profile of subjects with bipolar disorder
}

\author{
1 Bipolar Disorder Program, Institute of Neurosciences, Favaloro University, Buenos Aires, Argentina. \\ 2 Psychiatric Emergencies Hospital Torcuato de Alvear, Buenos Aires, Argentina. \\ ${ }^{3}$ National Council of Scientific and Technical Research (CONICET), Buenos Aires, Argentina. \\ ${ }_{4}$ School of Psychology, University of Buenos Aires, Buenos Aires, Argentina. \\ 5 Institute of Cognitive Neurology (INECO), Buenos Aires, Argentina.
}

Alejandro G. Szmulewicz',2, Ceeilia Samamé1,3,4, Diego J. Martino1,3, Sergio A. Strejilevich ${ }^{1,5}$

Received: 8/14/2015 - Accepted: 10/22/2015

DOI: 10.1590/0101-60830000000064

\begin{abstract}
Background: In recent years, growing interest in the neuropsychology of bipolar disorder has emerged, giving rise to the accumulation of a robust body of evidence on this topic and to several related questions. Objective: To provide a state-of-the-art overview of the neuropsychological profile of bipolar disorder. Method: A thorough literature search was performed. Published research evidence was summarized and organized along three key pathways: findings from cross-sectional studies of cognition in bipolar patients, cognitive heterogeneity among affected subjects, and trajectory of neuropsychological deficits. Results: At least two thirds of bipolar patients display neuropsychological deficits, even in euthymia. Although bipolar disorder was found to be associated with an increased risk of dementia, data from elderly subjects and longitudinal research do not support a worsening of cognitive performance over time. Discussion: Cognitive dysfunctions are part of the clinical conceptualization of bipolar illness. However, they may not be present in all affected subjects and their course appears to be stable in most cases. Available evidence may be highlighting the fact that bipolar disorder is characterized by remarkable heterogeneity regarding cognitive outcomes. Different variables may be related to such heterogeneity and should be the focus of therapeutic approaches and further research.
\end{abstract}

Szmulewicz AG et al. / Arch Clin Psychiatry. 2015;42(5):139-46

Keywords: Bipolar disorder, neuropsychological functioning, heterogeneity, evolution.

\section{Introduction}

Bipolar disorder (BD) is a complex chronic illness that affects mood and biological rhythms, causing subtle to severe distortions of normal behavior. BD is associated with significant functional impairment, even when appropriately treated and after symptomatic recovery is achieved 1,2 .

Poor functional outcomes have been shown to be strongly associated with persistent neuropsychological deficits ${ }^{3-5}$, which are currently acknowledged as an important feature of BD. Indeed, during the last decade, the long-held assumption of cognitive indemnity of $\mathrm{BD}$ was debunked as a result of compelling evidence for conspicuous cognitive deficits in a significant percentage of affected subjects, even during periods of euthymia ${ }^{6}$. Notwithstanding the release of copious amounts of research reports on this topic, the neuropsychological profile of the disorder remains unclear, and several related questions have arisen in the last few years.

The aim of this study was to integrate the pieces of evidence gathered at present in order to provide an updated review on cognitive functioning in $\mathrm{BD}$. The most controversial issues related to this subject were discussed, and targets for forthcoming research were highlighted.

\section{Methods}

First, an extensive computerized literature search was performed. Articles available with an abstract in English were retrieved from electronic databases (PubMed, PsychINFO, SciELO, and Lilacs), covering the period from January 1990 to August 2015. Afterwards, a narrative review was conducted, giving special consideration to large studies, systematic reviews, and, particularly, to meta-analyses, as the last allow for more precise estimates of effect magnitude than data derived from primary studies. In order to provide a comprehensive framework, the currently available evidence on neuropsychological functioning in BD was summarized and organized around three key topics: 1) neuropsychological profile of BD patients; 2) cognitive heterogeneity among bipolar subjects; and 3) longitudinal trajectory of cognitive deficits in BD.

\section{Results}

\section{Neuropsychological profile of BD}

In order to characterize a $\mathrm{BD}$ profile of neuropsychological performance, findings from both subjects in the premorbid phase of the disorder and patients with established illness are exhibited (Table 1). Among the latter, the findings of studies on subjects belonging to different age groups are reviewed.

\section{Findings in the premorbid phase of $B D$}

Neurocognitive functioning in the premorbid phase of the illness has been appraised by means of three methodologies: prospective conscript studies, evidence from birth cohorts and at-risk subjects followed longitudinally. Martino et al. ${ }^{7}$ reviewed the findings from these approaches and reported that with the exception of one study ${ }^{8}$, which showed that poor performance on visuospatial reasoning and increased performance on the arithmetic subtest were associated with $\mathrm{BD}$, studies failed to find any differences between people who were subsequently diagnosed with $\mathrm{BD}$ and healthy controls on measures of general intelligence ${ }^{9-11}$. In keeping, Trotta et al $^{12}$, in a meta-analysis of four prospective cohort studies, yielded a nonsignificant overall effect size for premorbid IQ in BD.

However, these studies assessed general intellectual function and not specific cognitive domains. Findings regarding the latter are scant so far. Meyer et al. ${ }^{13}$ used data from a 23-year longitudinal prospective study of offspring of mothers with $\mathrm{BD}$, unipolar depression or no history of $\mathrm{BD}(n=74)$. They were evaluated from 8 to 15 years with general intelligence tests, from 11 to 19 years with executive functions measures and as young adults with psychopathology measures (SCID-I). Offspring who were later diagnosed with BD during adulthood $(n=9)$ had lower performance than healthy controls on 
measures of executive functions with moderate-large effect sizes ( $d=0.58-1.34)$ at age $11-19$, although they had comparable IQ when they were 8-15 years old. Ratheesh et al. ${ }^{14}$ followed a cohort of 413 children who were at ultra-high risk for psychosis for a mean period of 8.2 years. Children who were later diagnosed with BD showed lower performance than healthy controls on measures of global intelligence, visuospatial ability and executive function with large effect sizes $(d=1.35-1.56)$. In keeping, Klimes-Dougan et al. ${ }^{15}$ conducted an extensive neuropsychological assessment of adolescent children of mothers with a history of BD $(n=43)$ or major depressive disorder $(n=72)$. They found that offspring of mothers with BD had poorer performance on the Wisconsin Card Sorting Test, which remained significant after adjusting for IQ and depressive/manic symptoms.

\section{Findings in pediatric and adolescent patients}

A systematic review on cognitive performance in pediatric $\mathrm{BD}$ patients ${ }^{16}$ reported that significant deficits in verbal/visual-spatial memory, processing speed, working memory and social cognition were found quite consistently across the primary studies included. Furthermore, two previous meta-analyses showed moderate deficits $(d=0.5-0.8)$ in verbal memory, attention, processing speed and executive domains among pediatric and adolescent patients ${ }^{17,18}$.

However, most of the primary studies included in these reviews were performed during affective episodes. Data on euthymic BD pediatric patients are very scant so far. At the primary study level, the largest study evaluating cognitive impairments in pediatric bipolar patients included 28 unmedicated patients during manic episode, medicated euthymic patients $(n=28)$ and healthy individuals $(n=$ $28)^{19}$. Both patient groups (mean age $=11.74, \mathrm{SD}=2.99$ ) showed large $(d \geq 0.8)$ impairments in domains of attention, executive functions, working memory and verbal memory compared to healthy controls. However, half of the patients in each group had comorbid ADHD, which made it difficult to identify deficits specific to pediatric BD.

\section{Findings in young and middle-aged adults}

Aggregate data meta-analyses of neurocognitive functioning in young and middle-aged adults ${ }^{20-26}$ have reported moderate $(d=0.5-0.8)$ and large $(d \geq 0.8)$ deficits across executive functions, verbal memory, attention and processing speed. However, the only individual patient data meta-analysis of cognition in $\mathrm{BD}(n=2876)$ conducted at present ${ }^{27}$ showed small-to-moderate deficits $(d=0.26-0.63)$ in most neurocognitive domains after controlling for age, premorbid IQ and gender. Furthermore, this study reported a large degree of heterogeneity across studies, which may explain some differences observed in the effect sizes yielded by previous meta-analyses.

Kurtz and Gerraty ${ }^{25}$ performed a meta-analysis evaluating the profile of neurocognitive impairment of $\mathrm{BD}$ patients and the impact of clinical episodes on those measures. The study combined results from 42 studies conducted in euthymic patients, 13 studies in manic/mixed phase and 5 studies of patients in a depressed state, suggesting that, although present during euthymia, a subset of these neurocognitive impairments would worsen during periods of acute affective episodes.

With regard to social cognitive domains, evidence for impaired emotion recognition and theory of mind in the three phases of $\mathrm{BD}$ is rather consistent across studies ${ }^{28}$. A recent meta-analysis of social cognition in euthymic bipolar patients ${ }^{29}$ showed no significant patient-control differences for the recognition of three basic emotions (happiness, sadness, and anger) whereas small but significant effect sizes favoring healthy controls $(d<0.5)$ were noted for emotional intelligence, the Hinting Task, the Eyes Test, and the recognition of fear, disgust, and surprise. Furthermore, this study showed a medium effect size of impairment $(d=0.58)$ for the Faux Pas Test. However, it is not yet clear whether these social cognitive flaws are epiphenomena of neurocognitive deficits. Finally, the only meta-analysis of studies assessing decision-making in samples composed exclusively of euthymic subjects ${ }^{30}$ reported no significant differences between controls and patients in the total net score of the Iowa Gambling Task. In contrast, primary studies of subjects during acute episodes revealed suboptimal task performance ${ }^{31,32}$ particularly during mania, suggesting that decision-making impairments are state-dependent in $\mathrm{BD}$ patients.

\section{Findings in elderly adults}

The only meta-analysis of neurocognition in late-life $\mathrm{BD}^{33}$ revealed moderate impairments for the cognitive variables analyzed, except for phonemic fluency $(d=0.80)$ and cognitive flexibility $(d=0.88)$. This report took into account the fact that older adults with $\mathrm{BD}$ constitute a heterogeneous population composed by both people with early-onset $\mathrm{BD}$ (EOBD), who developed their illness during adolescence/young adulthood, and people with late-onset BD (LOBD), who experienced their first affective episode at the age of 40 or over. These two subgroups may have different features. Typically, patients with LOBD show a weaker family history of affective disorders, higher frequency of neurological comorbidities, higher cardiovascular risk burden ${ }^{34-36}$ and worst neuropsychological performance on almost all measures ${ }^{37}$, suggesting a high influence of non-genetic etiological factors on this subgroup of patients. So, when meta-analysis was performed after removing the data from LOBD subjects and overall effect sizes were recalculated, estimates became much smaller ${ }^{33}$. A subsequent study ${ }^{38}$ showed that euthymic, non-demented elderly patients with BD performed worse than healthy controls on a verbal fluency test (semantic fluency-animal naming) with a large magnitude of impairment ( $d=$ 0.86). Furthermore, this study revealed that demented BD subjects had a significantly worse performance on the Clock Drawing Test as compared with patients with dementia due to Alzheimer's disease.

\section{Cognitive heterogeneity among subjects with $\mathrm{BD}$}

A recent study by Martino et al. ${ }^{39}$ showed that $30 \%$ of a sample of 100 $\mathrm{BD}$ patients was indistinguishable from healthy subjects in terms of cognitive functioning, whereas another $30 \%$ displayed more severe cognitive deficits than usually reported in the literature $(d=1.13)$. These findings are in keeping with other studies indicating that the prevalence of patients without clinically significant cognitive impairment fluctuates between $43 \%$ and $70 \%{ }^{40-44}$. Such results may be suggesting that primary studies and meta-analyses reporting mean values of neurocognitive functioning in BD patients might be failing to recognize that a subgroup of patients is demonstrating most of the impairment: while some patients might have a neurocognitive functioning within normal limits, others might show poorer performance than usually reported.

\section{Longitudinal course of cognitive deficits in $B D$}

In order to evaluate longitudinal trajectories of cognitive deficits in patients with $\mathrm{BD}$, four strategies were considered: studies of cognitive performance after first affective episode, longitudinal follow-up studies of cognitive functioning, data from patients with long illness duration, and evolution to dementia in subjects with BD (Table 2).

\section{Cognitive functioning in the first episode of $B D$}

Martino et al. ${ }^{7}$ reviewed 14 studies of cognitive performance in firstepisode patients, and reported that impairments in verbal memory, attention, and executive functions tended to be present during and after the first episode of the disorder. Considering only studies that evaluated patients during euthymia, after recovery of their first manic episode, Nehra et al.45 found impairments in IQ, executive functions, verbal memory and attention with large effect sizes for all measures. Torres et al. ${ }^{46}$ reported that patients with BD did not differ from controls with regard to premorbid IQ and attention, while moderate effect size impairments in executive functions, working 
Table 1. Meta-analyses of cognitive functioning in BD

\begin{tabular}{|c|c|c|c|}
\hline Meta- analysis & Study population & Mood state & Resultsa \\
\hline Arts et al. $(2008)^{22}$ & Adult patients and FDR & Euthymia & $\begin{array}{l}\text { BD: Large effect sizes for executive functions and verbal memory } \\
\text { Medium effect sizes for processing speed and sustained attention } \\
\text { Small effect sizes for visuoperception } \\
\text { FDR: small, but significant, effect sizes across cognitive domains }\end{array}$ \\
\hline Bora et al. (2009)23 & Adult patients and FDR & Euthymia & $\begin{array}{l}\text { BD: Moderate-to-large effect sizes for executive functions, sustained } \\
\text { attention and verbal memory } \\
\text { FDR: small, but significant, effect sizes across cognitive domains }\end{array}$ \\
\hline Bora et al. $(2011)^{24}$ & Adult patients & $\begin{array}{l}\text { Euthymia and depression } \\
\text { (mixed sample) }\end{array}$ & $\begin{array}{l}\text { Small-to-moderate effect sizes across all domains (BD II-only vs. } \\
\text { controls) } \\
\text { BD II less impaired than BD I on memory measures }\end{array}$ \\
\hline Bora and Pantelis (2015) $)^{49}$ & FEBD & $\begin{array}{l}\text { Euthymia and mood episodes } \\
\text { (mixed sample) }\end{array}$ & $\begin{array}{l}\text { Moderate effect sizes for attention, processing speed, verbal and visual } \\
\text { memory. Small effect sizes for most executive domains }\end{array}$ \\
\hline Bourne et al. $(2013)^{27}$ & Adult patients & Euthymia & $\begin{array}{l}\text { Small-to-moderate effect sizes for verbal memory, executive functions } \\
\text { and sustained attention }\end{array}$ \\
\hline $\begin{array}{l}\text { Garcia Nieto and Castellanos } \\
\text { (2011)18 }\end{array}$ & Pediatric patients & $\begin{array}{l}\text { Euthymia and mood episodes } \\
\text { (mixed sample) }\end{array}$ & $\begin{array}{l}\text { Moderate effect sizes for verbal memory, attention, processing speed } \\
\text { and executive domains }\end{array}$ \\
\hline Joseph et al. (2008)17 & Pediatric patients & $\begin{array}{l}\text { Euthymia and mood episodes } \\
\text { (mixed sample) }\end{array}$ & $\begin{array}{l}\text { Moderate-to-large effects for verbal memory, attention, executive } \\
\text { functions, working memory and verbal fluency. Small effects for I0 and } \\
\text { motor speed }\end{array}$ \\
\hline Kurtz and Gerraty $(2009)^{25}$ & Adult patients & $\begin{array}{l}\text { Euthymia } \\
\text { Manic episode } \\
\text { Depressive episode }\end{array}$ & $\begin{array}{l}\text { Euthymia: moderate effect sizes for attention, delayed memory and } \\
\text { executive functions. Large effect sizes for verbal learning } \\
\text { Depressive and manic episodes: more severe impairment in verbal } \\
\text { learning and phonemic fluency }\end{array}$ \\
\hline Lee et al. (2014)48 & FEBD & Euthymia and manic episode & $\begin{array}{l}\text { Medium-to-large deficits for psychomotor speed, attention, working } \\
\text { memory and cognitive flexibility } \\
\text { Small deficits for verbal learning and memory, attentional switching, } \\
\text { and verbal fluency. Medium-to-large deficit for response inhibition only } \\
\text { detected in non-euthymic cases }\end{array}$ \\
\hline Mann-Wrobel et al. (2011)26 & Adult patients & Euthymia & Moderate-to-large effect sizes across all domains \\
\hline Robinson et al. (2006)20 & Adult patients & Euthymia & $\begin{array}{l}\text { Large effect sizes for executive function and verbal learning. Medium } \\
\text { effect sizes for delayed recall, set-shifting, processing speed, sustained } \\
\text { attention and response inhibition. Small effect sizes for verbal fluency }\end{array}$ \\
\hline Torres et al. $(2007)^{21}$ & Adult patients & Euthymia & $\begin{array}{l}\text { Medium-to-large impairment for executive functions, attention, } \\
\text { processing speed and episodic memory }\end{array}$ \\
\hline Trotta et al $(2015)^{12}$ & $\begin{array}{l}\text { Subjects in the premorbid } \\
\text { stage of illness }\end{array}$ & Euthymia & $\begin{array}{l}\text { Non-significant overall effect size for } I Q \text { between subjects who } \\
\text { subsequently developed BD and those who did not develop any } \\
\text { disorder }\end{array}$ \\
\hline Samamé et al. (2012)30 & Adult patients & Euthymia & $\begin{array}{l}\text { Non-significant overall effect size for decision-making (lowa Gambling } \\
\text { Task). Small effect size for facial emotion recognition. Moderate effect } \\
\text { sizes for mentalizing domains }\end{array}$ \\
\hline Samamé et al. (2013)33 & Elderly patients & Euthymia & $\begin{array}{l}\text { Non-significant differences for the MMSE and CDT. Moderate effect } \\
\text { sizes for sustained attention, digit span, delayed recall, verbal fluency } \\
\text { and cognitive flexibility }\end{array}$ \\
\hline Samamé et al. (2015)229 & Adult patients & Euthymia & $\begin{array}{l}\text { Medium effect size for the Faux-Pas test. Non-significant differences } \\
\text { for the recognition of three emotions (happiness, anger and sadness). } \\
\text { Small effect size for the recognition of surprise, fear and disgust, } \\
\text { emotional intelligence and the Hinting task }\end{array}$ \\
\hline
\end{tabular}

aAll effect sizes favor healthy controls.

BD: bipolar disorder; FDR: first degree relatives; FEBD: first episode bipolar disorder; MMSE: Mini-Mental State Examination; CDT: Clock Drawing Test.

memory and visual reasoning were found. Finally, López-Jaramillo et al. ${ }^{47}$ showed that patients with BD performed worse than healthy controls on a measure of working memory with moderate effect size, without between-group differences for IQ, verbal memory, attention, processing speed and executive functions. These results are in line with two recent meta-analyses of cognitive functioning in BD patients after their first affective episode ${ }^{48,49}$, which showed widespread impairment. According to these quantitative reviews, the severity of impairment was generally comparable to that found in studies with patients after recurring episodes, with medium effect sizes for most neuropsychological variables.

However, another systematic review ${ }^{50}$ reported that BD patients in remission immediately after first manic episode did not display deficits in non-verbal memory and verbal fluency, whereas evidence for impairments in other neurocognitive domains was inconsistent across reports, with most studies revealing negative findings, except for working memory.

\section{Longitudinal studies}

The only meta-analysis summarizing the results of longitudinal studies of euthymic adults with BD did not show any significant differences between $\mathrm{BD}$ patients' performance at baseline and healthy controls after a mean follow-up period of 4.62 years for 14 cognitive variables ${ }^{51}$. In this line, a recent study analyzed the one-year trajectory of cognitive deficits in recently diagnosed BD and reported an improvement in processing speed and executive functions ${ }^{52}$. Similarly, Santos et al. ${ }^{53}$ found no differences in neuropsychological trajectory 
between patients and healthy controls after 5 years follow-up of a large sample of BD subjects. Another recent study followed prospectively a cohort of 71 major depressive disorder, $61 \mathrm{BD}$ and 35 schizophrenia patients, evaluated at baseline and after a mean of 20.6 months. The authors reported that, as a group, BD displayed stable cognitive functioning and even improved on a measure of verbal memory ${ }^{54}$. However, there are a number of limitations to be considered when analyzing these data. First, follow-up periods were relatively short in most studies and it should not be assumed that no cognitive decline occurred after this period. Another important limitation was that not all studies controlled for mood symptomatology at baseline and during follow-up. Therefore, changes in mood state could have influenced the results. Finally, longitudinal studies available at present only explored the trajectory of cognitive functioning in full-blown $\mathrm{BD}$, whereas the course of cognition in the period comprised between the premorbid stage of the disorder and the onset of mood symptoms remains unexplored.

\section{Patients with long illness duration}

Studies of cognitive performance in elderly patients with BD tended to find the same pattern of cognitive deficits both in terms of domain affected and magnitude reported in younger patients, suggesting indirectly no neurocognitive progression of the illness ${ }^{33}$. In order to assess the potential effect of illness progression on neurocognition, a study compared neurocognitive functioning between patients aged 40 years or younger (Y-BD) and patients aged 60 years or older (E-BD). Despite E-BD patients having illness duration almost four times longer than Y-BD patients, no significant differences in neurocognitive functioning were found between these two groups ${ }^{55}$.

A possible limitation of these studies is selection bias in samples of elderly BD patients, since those who developed dementia or severe cognitive impairment, might have been institutionalized or dead and therefore under-represented.

\section{Evolution to dementia}

Some small pioneering studies of non-euthymic bipolar elders found that a high percentage of them scored positively on screening tests for dementia ${ }^{56,57}$. In accordance with these findings, evidence from population-based studies showed that the diagnosis of BD was significantly associated with an increased risk of dementia ${ }^{58,59}$.

These results indicate that overall, there seems to be a percentage of people with $\mathrm{BD}$ that will develop dementia. However, this outcome may be present in around 6-9\% of BD patients included. Taking this into account, dementia might be an infrequent outcome rather than the average evolution of $\mathrm{BD}^{6}$.

\section{Discussion}

In this study, the available evidence on the neuropsychological profile of $\mathrm{BD}$ was reviewed in order to address some of the controversies regarding this matter. Our findings indicate that cognitive deficits are present in a significant percentage of affected subjects, even during euthymia periods and that they seem to exacerbate during acute mood episodes. Such impairments could be present prior to illness onset, and are evident in BD patients belonging to different age groups. Furthermore, some findings suggest that the magnitude of these deficits would be similar in young and elderly patients. These results are in line with preliminary findings from longitudinal studies, which do not reveal any changes in the neuropsychological performance of BD subjects over time.

At present, there appears to be a certain degree of agreement in the fact that neuropsychological performance is a major determinant of functional outcomes in BD patients. As shown in this review, although it is widely acknowledged that bipolar subjects exhibit neurocognitive impairments in domains of verbal memory, attention and executive functions, among others, the notion of cognitive impairment may not be applicable to all patients ${ }^{40,60}$. This cognitive heterogeneity might be explained by a number of environmental and genetic causes reported in the literature to alter normal cognitive functioning in BD patients such as obstetric complications ${ }^{61}$, genetic polymorphisms ${ }^{62}$, childhood trauma ${ }^{63}$, infection with Herpes Simplex virus type 164,65 , comorbidity with anxiety disorder ${ }^{66}$ or alcohol abuse $^{67-69}$, age at onset ${ }^{37,70}$, subclinical hypothyroidism ${ }^{71}$ and exposure to antipsychotics ${ }^{72,73}$.

Beyond the well-documented relationship between cognitive and functional outcomes in $\mathrm{BD}$, another variable that has been traditionally associated with cognitive performance is the number of previous episodes, especially manic ones ${ }^{74,75}$. This finding has led some authors to suggest a progressively deteriorating nature of cognitive deficits in BD. However, these data derive from cross-sectional studies, and therefore, the direction of causality cannot be ascertained. In fact, a recent prospective study 76 found that patients with clinically significant cognitive deficits had an increased risk of suffering any recurrence and suggested that severe cognitive impairment may be the cause, rather than the consequence, of a poorer course of illness, thus providing an alternative explanation to this relationship. This result may also be suggesting that the subgroups of patients with better clinical outcomes and with preserved cognitive function might overlap. Hence, the importance of this finding lies in the fact that cognitive heterogeneity might be a clue to explain the variability seen in areas like global functioning and course of illness, although the mechanisms underlying these associations are a matter of speculation nowadays. For example, patients with poor cognitive functioning might have poorer treatment adherence ${ }^{77}$, poorer response to

Table 2. Main approaches to the study of the longitudinal course of cognitive deficits in BD

\begin{tabular}{|l|l|l|}
\hline Methodological approach & Results & Main limitations \\
\hline $\begin{array}{l}\text { Cognitive functioning in first- } \\
\text { episode BD }\end{array}$ & $\begin{array}{l}\text { Inconsistent findings. Both impaired and preserved cognitive } \\
\text { outcomes have been reported48-50 }\end{array}$ & $\begin{array}{l}\text { Small sample sizes } \\
\text { Results potentially confounded by mood symptomatology }\end{array}$ \\
\hline Longitudinal research & $\begin{array}{l}\text { Longitudinal meta-analysis does not show any test-retest } \\
\text { differences for neurocognitive variables51 }\end{array}$ & $\begin{array}{l}\text { Short follow-up periods } \\
\text { Few data on healthy controls } \\
\text { Dropout bias } \\
\text { Results potentially confounded by mood symptomatology } \\
\text { Results only account for the course of cognitive deficits after illness } \\
\text { onset }\end{array}$ \\
\hline $\begin{array}{l}\text { Cognitive functioning in long- } \\
\text { standing BD }\end{array}$ & $\begin{array}{l}\text { Meta-analysis of cognition in E-BD subjects shows a pattern and } \\
\text { magnitude of impairment similar to those reported for young adult } \\
\text { patients33 } \\
\text { Comparison between Y-BD and E-BD reveals no significant } \\
\text { differences in cognitive performance55 }\end{array}$ & $\begin{array}{l}\text { Small sample sizes } \\
\text { Few studies performed on E-BD } \\
\text { BD patients with poor outcomes (dementia, institutionalized) } \\
\text { probably not included in E-BD samples }\end{array}$ \\
\hline Population-based studies & $\begin{array}{l}\text { An association between BD and an increased risk of dementia is } \\
\text { supported by available data58,59 }\end{array}$ & $\begin{array}{l}\text { These studies reflect the outcome of a minority of BD patients (6\%- } \\
\text { 9\%) }\end{array}$ \\
\hline
\end{tabular}

BD: bipolar disorder; E-BD: elderly BD patients (aged 60 years or above); Y-BD: young BD patients (aged 40 years or under). 
psychoeducation programs and psychotherapeutic interventions leading to poorer disease evolution and global functioning. Indeed, a previous study noted that cognition was probably a major source of uncontrolled variance regarding response to treatment ${ }^{41}$.

Despite these considerations, the aforementioned relationship between number of episodes and cognitive functioning 47,78 , together with several recent reports showing a tendency towards episode acceleration and the evidence of an increased risk of suffering dementia in bipolar subjects, has given rise to the notion of $\mathrm{BD}$ as a progressively deteriorating condition and the application of staging models to this group of disorders. In the context of the utilization of staging conceptualizations for the appraisal of severe psychiatric conditions, the term 'neuroprogression' has been coined to refer to a pathological reorganization of the central nervous system that would occur along the course of these illnesses ${ }^{79}$. Applied to BDs, the hypothesis of neuroprogression suggests that different characteristics of the disorder follow a progressive path from prodromic to more severe and refractory presentations ${ }^{80}$. However, it has not been adequately validated so far and several artifacts must be considered when interpreting the evidence often thought of as being 'in support' of this notion ${ }^{81}$. What is more, recent reports have emphatically stated that cognitive deficits are progressive in $\mathrm{BD}$ on the basis of the findings of cross-sectional studies ${ }^{82,83}$. According to these investigations, patients in later stages have worse functional outcome/higher number of episodes than subjects in early stages, who display better outcomes. Given the strong correlation between functional outcomes and cognitive functioning ${ }^{84-86}$, the finding of a worse neuropsychological performance in late-stage patients as defined on the basis of poor global functioning is predictable. However, it is not possible to infer neuroprogression from this, given that no longitudinal study at present has proved that the different presentations of BD are moments in the development of the disorder as the utilization of the word "stage" would necessarily imply. In fact, taken together, findings evaluating long-term evolution of cognitive deficits in $\mathrm{BD}$ do not support the hypothesis that cognitive deficits tend to worsen over the course of illness. Rather, it would be more sensible to conclude in the light of the currently available evidence that there are different subgroups within the disorder that may have different cognitive trajectories. Indeed, a meta-analysis by our group ${ }^{33}$, revealed that elderly BD subjects, with about three decades of illness duration and the longstanding exposure to variables which may negatively impact cognition, displayed a magnitude of impairment similar to that observed in young adult subjects with BD. Such finding may be indicating that the time being ill does not allow for any prediction on the cognitive outcomes nor the assumption of an evolving nature of the disorder. Instead, evidence available so far may be indicating the existence of different clinical subgroups within $\mathrm{BD}$, each having distinct features and cognitive trajectories. For example, data regarding evolution to dementia in BD suggests that only $6 \%-9 \%$ might have a poorer evolution and this malignant outcome.

Nevertheless, it is not yet possible to conclude from these findings that cognitive deficits are static over the course of BD. On the one hand, because the approaches utilized to the study of this issue have several methodological limitations. On the other hand, because cognitive decline could occur after the emergence of mood symptoms or at a preclinical stage and there are no studies assessing cognitive function in the same subjects both before and after the onset of the disorder. However, as shown in this review, neuropsychological studies using specific domain tasks, though scant, have not supported the hypothesis of preserved cognition in the premorbid stage. In spite of this, it could be hypothesized that whereas some patients present with cognitive impairment at the moment of their first affective episode, some patients do not, resulting in subgroups in terms of cognitive performance at the time of illness onset. Indeed, Mac Cabe et al. ${ }^{87}$ reported that both low and high grades in high school predicted future manic episodes, underscoring heterogeneity in cognitive functioning in adolescents prior to receiving a $\mathrm{BD}$ diagnosis. Thus, the evidence available at present shows that patients in the premorbid phase of $\mathrm{BD}$, as a whole, may not present with preserved cognitive functioning. However, cognitive outcomes may be heterogeneous among these patiens. Such preliminary findings do not support the hypothesis of progressive deterioration of cognition either and highlight the heterogeneous nature of $\mathrm{BD}$.

In view of the existing evidence on cognitive functioning in $\mathrm{BD}$, targets for future research are proposed. First, further studies of euthymic patients and subjects at risk for the disorder are needed in order to better clarify the neuropsychological profile of BD. For example, it is currently a matter of debate whether $\mathrm{BD}$ patients display an intermediate performance between subjects with schizophrenia and healthy controls or if the neuropsychological profiles of these disorders are qualitatively different. Recent preliminary findings support the latter notion ${ }^{39,88}$. Second, large longitudinal studies, with long follow-up periods, assessing specific cognitive domains in $\mathrm{BD}$ patients are clearly needed as well as studies of cognitive performance in the same subjects both after and before the onset of mood episodes in order to ascertain whether neuropsychological deficits worsen over time, and if so, to determine the moment in which cognitive decline would occur. Third, a number of variables found to be related to poorer cognitive outcomes should be studied more deeply. In addition, the relationship between mood episodes and cognitive dysfunction (i.e., as inductors of cognitive impairments or exacerbating existing cognitive dysfunctions) should be further assessed. Insights into cognitive subgroups in $\mathrm{BD}$ might also be useful. For example, prospective studies evaluating clinical course/ functional outcomes in newly diagnosed patients (i.e. after recovery of their first manic episode) or high-risk BD, divided by their cognitive performance might be useful in determining whether cognitive performance determines poor clinical outcomes or vice versa.

\section{Therapeutic implications of cognitive impairment in BD}

As neuropsychological impairment is currently acknowledged as an important target for therapeutic efforts, it is important that clinicians are aware of a number of variables that may affect cognitive outcomes.

At present, preclinical findings have suggested that lithium might have beneficial effect on cognition ${ }^{89-92}$. Although no direct evidence for a beneficial effect of this drug on cognitive impairment exists, preliminary findings report an association between the use of lithium and more preserved cognitive functioning. For instance, Nunes et al. ${ }^{93}$ compared the prevalence of Alzheimer's disease between a group of $\mathrm{BD}$ subjects treated chronically with lithium therapy and another group of patients without recent lithium therapy. They found that lithium-treated BD patients had lower prevalence of Alzheimer's disease and suggested that lithium treatment reduced the prevalence of Alzheimer's disease (AD) in BD patients to levels found in general elderly population. In keeping, a recent population-based cohort study evaluated dementia risk among BD adults on lithium therapy ${ }^{94}$. Compared with non-use, a year of lithium treatment was associated with significantly reduced dementia risk. Moreover, there is preliminary evidence of improved white matter integrity in BD patients ${ }^{95}$. However, contradictory results exist when evaluating literature on cognitive performance in specific domains in subjects under treatment with lithium. Recent studies compared the neuropsychological performance of patients treated with and without lithium and found significant differences favoring the former ${ }^{96,97}$. On the other hand, prolonged administration of lithium has also been associated with discrete negative effects in learning, surveillance, alert and short-term memory ${ }^{98}$. In keeping, a meta-analysis comparing healthy volunteers and affective disorder patients reported that lithium had a small, but significant, deleterious effect on immediate verbal learning, memory and creativity, with no significant effect on other measures ${ }^{99}$ ). Taken together, this findings point towards a modest, if any, effect of lithium on traditional neurocognitive measures.

On the other hand, there is evidence from healthy subjects, BD and other clinical populations suggesting that exposure to different psychotropic agents commonly prescribed to bipolar patients is 
associated with impaired cognition $73,100-104$. In the same line, obesity and metabolic syndrome induced by atypical antipsychotics may further influence cognitive functioning ${ }^{105,106}$. Thus, it is also possible that patients responding to lithium treatment are less exposed to antipsychotics and better cognitive outcomes are a reflection of that.

To further support this, studies comparing cognitive performance between drug-free BD patients during euthymia and healthy controls show less impairment than reported in studies that included treated patients. Joffe et al. ${ }^{107}$ found no differences between drug-free BD patients and healthy controls in measures of attention and verbal memory. Also, no differences were found when comparing drug-free patients with lithium-treated patients. López-Jaramillo et al. 108 found differences only in measures of verbal, logical and working memory while non-medicated patients performed as well as healthy controls on other traditional neurocognitive measures. The subgroup of BD patients under treatment with lithium performed equally as those without pharmacological treatment on all measures. Finally, Torrent et al. ${ }^{73}$ found no differences in neurocognitive performance between drug-free BD patients and healthy controls except for one test, the TMT-B, which evaluates executive functions. Despite some limitations, like small sample sizes and a possible selection bias of highly selected sample of patients with good outcomes, these results point towards some sort of iatrogenic-pharmacologic effect of medication on cognitive performance affecting treated BD patients usually included in studies ${ }^{73}$.

Taking together findings from drug-free patients and cognitive heterogeneity in $\mathrm{BD}$, initially, it should not be assumed that cognitive deficits are necessarily present in the course of the disorder. Clinicians should rule out potentially treatable causes of these deficits such as clinical (i.e., hypothyroidism or metabolic syndrome) or psychiatric (i.e., anxiety disorders or abuse/dependence of alcohol) comorbidities among patients with clinically significant cognitive impairments. Likewise, this subgroup of patients may not be candidate for receiving drugs such as benzodiazepines, anticholinergic agents or antipsychotics with a negative impact on cognition $72,102,109$. On the other hand, the efficacy of psychosocial interventions may be influenced by cognitive status, although this has not been formally studied so far.

In conclusion, cognitive deficits in $\mathrm{BD}$ are of paramount importance as they may represent a bridge between symptomatic remission and functional recovery that could be targeted by therapeutic interventions. They may also constitute a useful tool for predicting clinical and functional outcomes to individual patients, a great difficulty that many clinicians acknowledge when treating subjects with BD. Finally, as stated above, cognitive performance and related variables should be taken into account at the time of selecting proper pharmacological treatment to an individual patient.

\section{Conflict of interest}

None.

\section{References}

1. Tohen M, Strakowski SM, Zarate C Jr, Hennen J, Stoll AL, Suppes T, et al. The McLean-Harvard first-episode project: 6-month symptomatic and functional outcome in affective and nonaffective psychosis. Biol Psychiatry. 2000;48(6):467-76.

2. Wingo AP, Baldessarini RJ, Holtzheimer PE, Harvey PD. Factors associated with functional recovery in bipolar disorder patients. Bipolar Disord. 2010;12(3):319-26.

3. Martino DJ, Marengo E, Igoa A, Scápola M, Ais ED, Perinot L, et al. Neurocognitive and symptomatic predictors of functional outcome in bipolar disorders: a prospective 1 year follow-up study. J Affect Disord. 2009;116(1-2):37-42.

4. Burdick KE, Goldberg JF, Harrow M. Neurocognitive dysfunction and psychosocial outcome in patients with bipolar I disorder at 15-year follow-up. Acta Psychiatr Scand. 2010;122(6):499-506.

5. Depp CA, Mausbach BT, Harmell AL, Savla GN, Bowie CR, Harvey PD, et al. Meta-analysis of the association between cognitive abilities and everyday functioning in bipolar disorder. Bipolar Disord. 2012;14(3):217-26.
6. Strejilevich SA, Samamé C, Martino DJ. The trajectory of neuropsychological dysfunctions in bipolar disorders: a critical examination of a hypothesis. J Affect Disord. 2015;175:396-402.

7. Martino DJ, Samamé C, Ibañez A, Strejilevich SA. Neurocognitive functioning in the premorbid stage and in the first episode of bipolar disorder: a systematic review. Psychiatry Res. 2015;226(1):23-30.

8. Tiihonen J, Haukka J, Henriksson M, Cannon M, Kieseppä T, Laaksonen I, et al. Premorbid intellectual functioning in bipolar disorder and schizophrenia: results from a cohort study of male conscripts. Am J Psychiatry. 2005;162(10):1904-10.

9. Reichenberg A, Weiser M, Rabinowitz J, Caspi A, Schmeidler J, Mark $\mathrm{M}$, et al. A population-based cohort study of premorbid intellectual, language, and behavioral functioning in patients with schizophrenia, schizoaffective disorder, and nonpsychotic bipolar disorder. Am J Psychiatry. 2002;159(12):2027-35.

10. Zammit S, Allebeck P, David AS, Dalman C, Hemmingsson T, Lundberg I, et al. A longitudinal study of premorbid IQ Score and risk of developing schizophrenia, bipolar disorder, severe depression, and other nonaffective psychoses. Arch Gen Psychiatry. 2004;61(4):354-60.

11. Sørensen HJ, Sæbye D, Urfer-Parnas A, Mortensen EL, Parnas J. Premorbid intelligence and educational level in bipolar and unipolar disorders: a Danish draft board study. J Affect Disord. 2012;136(3):1188-91.

12. Trotta A, Murray RM, MacCabe JH. Do premorbid and post-onset cognitive functioning differ between schizophrenia and bipolar disorder? A systematic review and meta-analysis. Psychol Med. 2015;45(2):381-94.

13. Meyer SE, Carlson GA, Wiggs EA, Martinez PE, Ronsaville DS, KlimesDougan B, et al. A prospective study of the association among impaired executive functioning, childhood attentional problems, and the development of bipolar disorder. Dev Psychopathol. 2004;16(2):461-76.

14. Ratheesh A, Lin A, Nelson B, Wood SJ, Brewer W, Betts J, et al. Neurocognitive functioning in the prodrome of mania - an exploratory study. J Affect Disord. 2013;147(1-3):441-5.

15. Klimes-Dougan B, Ronsaville D, Wiggs EA, Martinez PE. Neuropsychological functioning in adolescent children of mothers with a history of bipolar or major depressive disorders. Biol Psychiatry. 2006;60(9):957-65.

16. Frías Á, Palma C, Farriols N. Neurocognitive impairments among youth with pediatric bipolar disorder: a systematic review of neuropsychological research. J Affect Disord. 2014;166:297-306.

17. Joseph MF, Frazier TW, Youngstrom EA, Soares JC. A quantitative and qualitative review of neurocognitive performance in pediatric bipolar disorder. J Child Adolesc Psychopharmacol. 2008;18(6):595-605.

18. Nieto RG, Castellanos FX. A meta-analysis of neuropsychological functioning in patients with early onset schizophrenia and pediatric bipolar disorder. J Clin Child Adolesc Psychol. 2011;40(2):266-80.

19. Pavuluri MN, Schenkel LS, Aryal S, Harral EM, Hill SK, Herbener ES, et al. Neurocognitive function in unmedicated manic and medicated euthymic pediatric bipolar patients. Am J Psychiatry. 2006;163(2):286-93.

20. Robinson LJ, Thompson JM, Gallagher P, Goswami U, Young AH, Ferrier IN, et al. A meta-analysis of cognitive deficits in euthymic patients with bipolar disorder. J Affect Disord. 2006;93(1-3):105-15.

21. Torres IJ, Boudreau VG, Yatham LN. Neuropsychological functioning in euthymic bipolar disorder: a meta-analysis. Acta Psychiatr Scand Suppl. 2007;(434):17-26.

22. Arts B, Jabben N, Krabbendam L, van Os J. Meta-analyses of cognitive functioning in euthymic bipolar patients and their first-degree relatives. Psychol Med. 2008;38(6):771-85.

23. Bora E, Yucel M, Pantelis C. Cognitive endophenotypes of bipolar disorder: a meta-analysis of neuropsychological deficits in euthymic patients and their first-degree relatives. J Affect Disord. 2009;113(1-2):1-20.

24. Bora E, Yücel M, Pantelis C, Berk M. Meta-analytic review of neurocognition in bipolar II disorder. Acta Psychiatr Scand. 2011;123(3):165-74.

25. Kurtz MM, Gerraty RT. A meta-analytic investigation of neurocognitive deficits in bipolar illness: profile and effects of clinical state. Neuropsychology. 2009;23(5):551-62.

26. Mann-Wrobel MC, Carreno JT, Dickinson D. Meta-analysis of neuropsychological functioning in euthymic bipolar disorder: an update and investigation of moderator variables. Bipolar Disord. 2011;13(4):334-42.

27. Bourne C, Aydemir Ö, Balanzá-Martínez V, Bora E, Brissos S, Cavanagh JT, et al. Neuropsychological testing of cognitive impairment in euthymic bipolar disorder: an individual patient data meta-analysis. Acta Psychiatr Scand. 2013;128(3):149-62. 
28. Samamé C. Social cognition throughout the three phases of bipolar disorder: a state-of-the-art overview. Psychiatry Res. 2013;210(3):1275-86.

29. Samamé C, Martino DJ, Strejilevich SA. An individual task meta-analysis of social cognition in euthymic bipolar disorders J Affect Disord. 2015;173:146-53.

30. Samamé C, Martino DJ, Strejilevich SA. Social cognition in euthymic bipolar disorder: systematic review and meta-analytic approach. Acta Psychiatr Scand. 2012;125(4):266-80.

31. Murphy FC, Rubinsztein JS, Michael A, Rogers RD, Robbins TW, Paykel ES, et al. Decision-making cognition in mania and depression. Psychol Med. 2001;31(4):679-93.

32. Adida M, Jollant F, Clark L, Besnier N, Guillaume S, Kaladjian A, et al. Trait-related decision-making impairment in the three phases of bipolar disorder. Biol Psychiatry. 2011;70(4):357-65.

33. Samamé C, Martino DJ, Strejilevich SA. A quantitative review of neurocognition in euthymic late-life bipolar disorder. Bipolar Disord. 2013;15(6):633-44.

34. Schürhoff F, Bellivier F, Jouvent R, Mouren-Siméoni MC, Bouvard M, Allilaire JF, et al. Early and late onset bipolar disorders: two different forms of manic-depressive illness? J Affect Disord. 2000;58(3):215-21.

35. Moorhead SR, Young AH. Evidence for a late onset bipolar-I disorder sub-group from 50 years. J Affect Disord. 2003;73(3):271-7.

36. Depp CA, Jeste DV. Bipolar disorder in older adults: a critical review. Bipolar Disord. 2004;6(5):343-67.

37. Martino DJ, Strejilevich SA, Manes F. Neurocognitive functioning in early-onset and late-onset older patients with euthymic bipolar disorder. Int J Geriatr Psychiatry. 2013;28(2):142-8.

38. Aprahamian I, Ladeira RB, Diniz BS, Forlenza OV, Nunes PV. Cognitive impairment in euthymic older adults with bipolar disorder: a controlled study using cognitive screening tests. Am J Geriatr Psychiatry. 2014;22(4):389-97.

39. Martino DJ, Strejilevich SA, Marengo E, Ibañez A, Scápola M, Igoa A. Toward the identification of neurocognitive subtypes in euthymic patients with bipolar disorder. J Affect Disord. 2014;167:118-24.

40. Martino DJ, Strejilevich SA, Scápola M, Igoa A, Marengo E, Ais ED, et al. Heterogeneity in cognitive functioning among patients with bipolar disorder. J Affect Disord. 2008;109(1-2):149-56.

41. Gualtieri CT, Morgan DW. The frequency of cognitive impairment in patients with anxiety, depression, and bipolar disorder: an unaccounted source of variance in clinical trials. J Clin Psychiatry. 2008;69(7):1122-30.

42. Reichenberg A, Harvey PD, Bowie CR, Mojtabai R, Rabinowitz J, Heaton $\mathrm{RK}$, et al. Neuropsychological function and dysfunction in schizophrenia and psychotic affective disorders. Schizophr Bull. 2009;35:1022-9.

43. Iverson GL, Brooks BL, Langenecker SA, Young AH. Identifying a cognitive impairment subgroup in adults with mood disorders. J Affect Disord. 2011;132(3):360-7.

44. Burdick KE, Braga RJ, Gopin CB, Malhotra AK. Dopaminergic influences on emotional decision making in euthymic bipolar patients. Neuropsychopharmacology. 2014;39(2):274-82.

45. Nehra R, Chakrabarti S, Pradhan BK, Khehra N. Comparison of cognitive functions between first- and multi-episode bipolar affective disorders. J Affect Disord. 2006;93(1-3):185-92.

46. Torres IJ, DeFreitas VG, DeFreitas CM, Kauer-Sant'Anna M, Bond DJ, Honer WG, et al. Neurocognitive functioning in patients with bipolar I disorder recently recovered from a first manic episode. J Clin Psychiatry. 2010;71(9):1234-42.

47. López-Jaramillo C, Lopera-Vásquez J, Gallo A, Ospina-Duque J, Bell V, Torrent $\mathrm{C}$, et al. Effects of recurrence on the cognitive performance of patients with bipolar I disorder: implications for relapse prevention and treatment adherence. Bipolar Disord. 2010;12(5):557-67.

48. Lee RS, Hermens DF, Scott J, Redoblado-Hodge MA, Naismith SL, Lagopoulos J, et al. A meta-analysis of neuropsychological functioning in first-episode bipolar disorders. J Psychiatr Res. 2014;57:1-11.

49. Bora E, Pantelis C. Meta-analysis of cognitive impairment in first-episode bipolar disorder: comparison with first-episode schizophrenia and healthy controls. Schizophr Bull. 2015. [Epub ahead of print]

50. Daglas R, Yücel M, Cotton S, Allott K, Hetrick S, Berk M. Cognitive impairment in first-episode mania: a systematic review of the evidence in the acute and remission phases of the illness. Int J Bipolar Disord. 2015;3:9.

51. Samamé C, Martino DJ, Strejilevich SA. Longitudinal course of cognitive deficits in bipolar disorder: a meta-analytic study. J Affect Disord. 2014;164:130-8.
52. Torres IJ, Kozicky J, Popuri S, Bond DJ, Honer WG, Lam RW, et al. 12-month longitudinal cognitive functioning in patients recently diagnosed with bipolar disorder. Bipolar Disord. 2014;16(2):159-71.

53. Santos JL, Aparicio A, Bagney A, Sánchez-Morla EM, Rodríguez-Jiménez $\mathrm{R}$, Mateo J, et al. A five-year follow-up study of neurocognitive functioning in bipolar disorder. Bipolar Disord. 2014;16(7):722-31.

54. Lee RS, Hermens DF, Naismith SL, Lagopoulos J, Jones A, Scott J, et al. Neuropsychological and functional outcomes in recent-onset major depression, bipolar disorder and schizophrenia-spectrum disorders: a longitudinal cohort study. Transl Psychiatry. 2015;5:e555.

55. Strejilevich SA, Martino DJ. Cognitive function in adulthood and elderly euthymic bipolar patients: a comparison to test models of cognitive evolution. J Affect Disord. 2013;150(3):1188-91.

56. Dhingra U, Rabins PV. Mania in the elderly: a 5-7 year follow-up. J Am Geriatr Soc. 1991;39(6):581-3.

57. Gildengers AG, Butters MA, Seligman K, McShea M, Miller MD, Mulsant $\mathrm{BH}$, et al. Cognitive functioning in late-life bipolar disorder. Am J Psychiatry. 2004;161(4):736-8.

58. Kessing LV, Olsen EW, Mortensen PB, Andersen PK. Dementia in affective disorder: a case-register study. Acta Psychiatr Scand. 1999;100(3):176-85.

59. Wu KY, Chang CM, Liang HY, Wu CS, Chia-Hsuan Wu E, Chen CH, et al. Increased risk of developing dementia in patients with bipolar disorder: a nested matched case-control study. Bipolar Disord. 2013;15(7):787-94.

60. Goldberg JF, Harrow M. Consistency of remission and outcome in bipolar and unipolar mood disorders: a 10-year prospective follow-up. J Affect Disord. 2004;81(2):123-31.

61. Martino DJ, Igoa A, Marengo E, Scápola M, Ais ED, Strejilevich SA. Cognitive and motor features in elderly people with bipolar disorder. J Affect Disord. 2008;105(1-3):291-5.

62. Zhao L, Lin Y, Lao G, Wang Y, Guan L, Wei J, et al. Association study of dopamine receptor genes polymorphism with cognitive functions in bipolar I disorder patients. J Affect Disord. 2015;170:85-90.

63. Savitz JB, van der Merwe L, Stein DJ, Solms M, Ramesar RS. Neuropsychological task performance in bipolar spectrum illness: genetics, alcohol abuse, medication and childhood trauma. Bipolar Disord. 2008;10(4):479-94.

64. Dickerson F, Stallings C, Sullens A, Origoni A, Leister F, Krivogorsky $\mathrm{B}$, et al. Association between cognitive functioning, exposure to Herpes Simplex Virus type 1, and the COMT Val158Met genetic polymorphism in adults without a psychiatric disorder. Brain Behav Immun. 2008;22(7):1103-7.

65. Gerber SI, Krienke UJ, Biedermann NC, Grunze H, Yolken RH, Dittmann S, et al. Impaired functioning in euthymic patients with bipolar disorder--HSV-1 as a predictor. Prog Neuropsychopharmacol Biol Psychiatry. 2012;36(1):110-6.

66. Wu HI, Chang YH, Lai CC, Wu JY, Chen SL, Chu CH, et al. The effect of comorbid anxiety disorder on neuropsychological function in bipolar II disorder. Prog Neuropsychopharmacol Biol Psychiatry. 2011;35(8):1841-5.

67. van Gorp WG, Altshuler L, Theberge DC, Wilkins J, Dixon W. Cognitive impairment in euthymic bipolar patients with and without prior alcohol dependence. A preliminary study. Arch Gen Psychiatry. 1998;55(1):41-6.

68. Levy B, Monzani BA, Stephansky MR, Weiss RD. Neurocognitive impairment in patients with co-occurring bipolar disorder and alcohol dependence upon discharge from inpatient care. Psychiatry Res. 2008;161(1):28-35.

69. Sanchez-Moreno J, Martinez-Aran A, Colom F, Scott J, Tabares-Seisdedos R, Sugranyes G, et al. Neurocognitive dysfunctions in euthymic bipolar patients with and without prior history of alcohol use. J Clin Psychiatry. 2009;70(8):1120-7.

70. Schouws SNTM, Comijs HC, Stek ML, Dekker J, Oostervink F, Naarding P, et al. Cognitive impairment in early and late bipolar disorder. Am J Geriatr Psychiatry. 2009;17(6):508-15.

71. Martino DJ, Strejilevich SA. Subclinical hypothyroidism and neurocognitive functioning in bipolar disorder. J Psychiatr Res. 2015;61:166-7.

72. Frangou S, Donaldson S, Hadjulis M, Landau S, Goldstein LH. The Maudsley Bipolar Disorder Project: executive dysfunction in bipolar disorder I and its clinical correlates. Biol Psychiatry. 2005;58(11):859-64.

73. Torrent C, Martinez-Arán A, Daban C, Amann B, Balanzá-Martínez V, del Mar Bonnín C, et al. Effects of atypical antipsychotics on neurocognition in euthymic bipolar patients. Compr Psychiatry. 2011;52(6):613-22.

74. Robinson LJ, Ferrier IN. Evolution of cognitive impairment in bipolar disorder: a systematic review of cross-sectional evidence. Bipolar Disord. 2006;8(2):103-16. 
75. Post RM, Fleming J, Kapczinski F. Neurobiological correlates of illness progression in the recurrent affective disorders. J Psychiatr Res. 2012;46(5):561-73.

76. Martino DJ, Strejilevich SA, Marengo E, Igoa A, Fassi G, Teitelbaum J, et al. Relationship between neurocognitive functioning and episode recurrences in bipolar disorder. J Affect Disord. 2013;147(1-3):345-51.

77. Martinez-Aran A, Scott J, Colom F, Torrent C, Tabares-Seisdedos R, Daban C, et al. Treatment nonadherence and neurocognitive impairment in bipolar disorder. J Clin Psychiatry. 2009;70(7):1017-23.

78. Elshahawi HH, Essawi H, Rabie MA, Mansour M, Beshry ZA, Mansour AN. Cognitive functions among euthymic bipolar I patients after a single manic episode versus recurrent episodes. J Affect Disord. 2011;130(12):180-91.

79. Berk M, Berk L, Dodd S, Cotton S, Macneil C, Daglas R, et al. Stage managing bipolar disorder. Bipolar Disord. 2014;16(5):471-7.

80. Kapczinski F, Magalhães PV, Balanzá-Martinez V, Dias VV, Frangou S, Gama CS, et al. Staging systems in bipolar disorder: an International Society for Bipolar Disorders Task Force Report. Acta Psychiatr Scand. 2014;130(5):354-63.

81. Martino DJ, Samamé C, Marengo E, Igoa A, Strejilevich S. Is bipolar disorder a neuroprogressive condition? A critical review of the clinical evidence. 2015. Submitted.

82. Rosa AR, Magalhães PV, Czepielewski L, Sulzbach MV, Goi PD, Vieta $\mathrm{E}$, et al. Clinical staging in bipolar disorder: focus on cognition and functioning. J Clin Psychiatry. 2014;75(5):e450-6.

83. Czepielewski LS, Massuda R, Goi P, Sulzbach-Vianna M, Reckziegel R, Costanzi M, et al. Verbal episodic memory along the course of schizophrenia and bipolar disorder: a new perspective. Eur Neuropsychopharmacol. 2015;25(2):169-75.

84. Martínez-Arán A, Vieta E, Colom F, Torrent C, Sánchez-Moreno J, Reinares $\mathrm{M}$, et al. Cognitive impairment in euthymic bipolar patients: implications for clinical and functional outcome. Bipolar Disord. 2004;6(3):224-32.

85. Torres IJ, DeFreitas CM, DeFreitas VG, Bond DJ, Kunz M, Honer WG, et al. Relationship between cognitive functioning and 6-month clinical and functional outcome in patients with first manic episode bipolar I disorder. Psychol Med. 2011;41(5):971-82.

86. Pattanayak RD, Sagar R, Mehta M. Neuropsychological performance in euthymic Indian patients with bipolar disorder type I: correlation between quality of life and global functioning. Psychiatry Clin Neurosci. 2012;66(7):553-63.

87. MacCabe JH, Lambe MP, Cnattingius S, Sham PC, David AS, Reichenberg A, et al. Excellent school performance at age 16 and risk of adult bipolar disorder: national cohort study. Br J Psychiatry. 2010;196(2):109-15.

88. Lee J, Altshuler L, Glahn DC, Miklowitz DJ, Ochsner K, Green MF. Social and nonsocial cognition in bipolar disorder and schizophrenia: relative levels of impairment. Am J Psychiatry. 2013;170(3):334-41.

89. Nocjar C, Hammonds MD, Shim SS. Chronic lithium treatment magnifies learning in rats. Neuroscience. 2007;150(4):774-88.

90. Tsaltas E, Kyriazi T, Poulopoulou C, Kontis D, Maillis A. Enhancing effects of lithium on memory are not by-products of learning or attentional deficits. Behav Brain Res. 2007;180(2):241-5.

91. Tsaltas E, Kontis D, Boulougouris V, Papakosta VM, Giannou H, Poulopoulou $\mathrm{C}$, et al. Enhancing effects of chronic lithium on memory in the rat. Behav Brain Res. 2007;177(1):51-60.

92. Li Q, Li H, Roughton K, Wang X, Kroemer G, Blomgren K, et al. Lithium reduces apoptosis and autophagy after neonatal hypoxia-ischemia. Cell Death Dis. 2010 Jul 15;1:e56.
93. Nunes PV, Forlenza OV, Gattaz WF. Lithium and risk for Alzheimer's disease in elderly patients with bipolar disorder. Br J Psychiatry. 2007;190:359-60.

94. Gerhard T, Devanand DP, Huang C, Crystal S, Olfson M. Lithium treatment and risk for dementia in adults with bipolar disorder: populationbased cohort study. Br J Psychiatry. 2015;207(1):46-51.

95. Gildengers AG, Butters MA, Aizenstein HJ, Marron MM, Emanuel J, Anderson SJ, et al. Longer lithium exposure is associated with better white matter integrity in older adults with bipolar disorder. Bipolar Disord. 2015;17(3):248-56.

96. Adida M, Jollant F, Clark L, Guillaume S, Goodwin GM, Azorin JM, et al. Lithium might be associated with better decision-making performance in euthymic bipolar patients. Eur Neuropsychopharmacol. 2015;25(6):788-97.

97. Muralidharan K, Kozicky JM, Bücker J, Silveira LE, Torres IJ, Yatham LN Are cognitive deficits similar in remitted early bipolar I disorder patients treated with lithium or valproate? Data from the STOP-EM study. Eur Neuropsychopharmacol. 2015;25(2):223-30.

98. Aprahamian I, Teixeira de Sousa R, Valiengo LCL, Machado-Vieira R, Forlenza OV. Lithium safety and tolerability in mood disorders: a critical review. Arch Clin Psychiatry. 2014;41(1):9-14.

99. Wingo AP, Wingo TS, Harvey PD, Baldessarini RJ. Effects of lithium on cognitive performance: a meta-analysis. J Clin Psychiatry. 2009;70(11):1588-97.

100. Ferrara SD, Giorgetti R, Zancaner S, Orlando R, Tagliabracci A, Cavarzeran $\mathrm{F}$, et al. Effects of single dose of gamma-hydroxybutyric acid and lorazepam on psychomotor performance and subjective feelings in healthy volunteers. Eur J Clin Pharmacol. 1999;54(11):821-7.

101. Goldberg JF, Burdick KE. Cognitive side effects of anticonvulsants. J Clin Psychiatry. 2001;62 Suppl 14:27-33.

102. Donaldson S, Goldstein LH, Landau S, Raymont V, Frangou S. The Maudsley Bipolar Disorder Project: the effect of medication, family history, and duration of illness on IQ and memory in bipolar I disorder. J Clin Psychiatry. 2003;64(1):86-93.

103. Jamrozinski K, Gruber O, Kemmer C, Falkai P, Scherk H. Neurocognitive functions in euthymic bipolar patients. Acta Psychiatr Scand. 2009;119(5):365-74.

104. Pålsson E, Figueras C, Johansson AG, Ekman CJ, Hultman B, Östlind $\mathrm{J}$, et al. Neurocognitive function in bipolar disorder: a comparison between bipolar I and II disorder and matched controls. BMC Psychiatry. 2013 J;13:165.

105. Yim CY, Soczynska JK, Kennedy SH, Woldeyohannes HO, Brietzke E, McIntyre RS. The effect of overweight/obesity on cognitive function in euthymic individuals with bipolar disorder. Eur Psychiatry. 2012;27(3):223-8.

106. Depp CA, Strassnig M, Mausbach BT, Bowie CR, Wolyniec P, Thornquist $\mathrm{MH}$, et al. Association of obesity and treated hypertension and diabetes with cognitive ability in bipolar disorder and schizophrenia. Bipolar Disord. 2014;16(4):422-31.

107. Joffe RT, MacDonald C, Kutcher SP. Lack of differential cognitive effects of lithium and carbamazepine in bipolar affective disorder. J Clin Psychopharmacol. 1988;8(6):425-8.

108. López-Jaramillo C, Lopera-Vásquez J, Ospina-Duque J, García J, Gallo A, Cortez V, et al. Lithium treatment effects on the neuropsychological functioning of patients with bipolar I disorder. J Clin Psychiatry. 2010;71(8):1055-60.

109. Mintzer MZ, Griffiths RR. Lorazepam and scopolamine: A single-dose comparison of effects on human memory and attentional processes. Exp Clin Psychopharmacol. 2003;11(1):56-72. 